Anales de Geografía de la Universidad Complutense ISSN: 0211-9803

http://dx.doi.org/10.5209/AGUC.69336

\title{
La participación ciudadana, factor asociado al desarrollo del turismo sostenible: caso ciudad de Ibagué (Colombia)
}

\author{
Cecilia Murcia García ${ }^{1}$ John Freddy Ramírez-Casallas ${ }^{2}$; Oscar Camilo Valderrama Riveros ${ }^{3}$ \\ Recibido: 22 de noviembre del 2017 / Enviado a evaluar: 25 de enero del 2018 / Aceptado: 9 de diciembre del 2019
}

Resumen. Abordando el desarrollo turístico en la ciudad de Ibagué, desde el ámbito de la sostenibilidad, propiamente la dimen-sión social, la dinámica de la participación ciudadana representa un papel clave. El ejercicio se apoya en un estudio de caso que indaga sobre participación ciudadana, considerándose la comunidad un factor asociado para el desarrollo del turismo sostenible en la ciudad. Los resultados, obtenidos a través de una técnica de análisis de contenido a información recopilada mediante encuesta, reflejan posiciones subjetivas que permean problemas en la participación. En las consideraciones finales se presenta un diagrama Iceberg construido a partir de niveles que evidencian problemas y falencias que han impedido consolidar una oferta y vocación turística en la ciudad de Ibagué. Tomando como base los modelos mentales identificados, se señala un bucle retroalimentador entre partidos políticos y ciudadanos, que inhibe la participación y hunde sus raíces en la discusión sobre la importancia del desarrollo local.

Palabras clave: Participación ciudadana; turismo sostenible; desarrollo; política pública; municipio.

\section{[en] The citizen participation, factor associated with the development of sustainable tourism: case Ibagué City (Colombia)}

\begin{abstract}
Tourism development from the field of sustainability focused on the social dimension and the dynamics of citizen participation represent a key role in the city of Ibague. This paper is supported by a case study that investigates citizen participation. Where the community is considered an associated factor for the development of sustainable tourism in the city. The results were obtained through a technique of content analysis to information collected through survey. These results reflect subjective positions that permeate problems in participation. In the final considerations an Iceberg diagram is presented. Which was built from levels that show problems and failure. These have prevented consolidating an offer and tourist vocation in the city of Ibagué. Based on the mental models identified, a feedback loop between
\end{abstract}

1 Universidad Cooperativa de Colombia, sede Ibagué (Colombia).

E-mail: cecilia.murcia@campusucc.edu.co

2 Universidad Cooperativa de Colombia, sede Ibagué (Colombia).

E-mail: john.ramirez@campusucc.edu.co

3 Universidad Cooperativa de Colombia, sede Ibagué (Colombia).

E-mail: oscar.valderramar@campusucc.edu.co 
political parties and citizens is signaled. That inhibits participation and has its roots in the discussion about the im-portance of local development.

Keywords: Citizen Participation; sustainable tourism; development; public policy; municipality.

\section{[fr] la participation citoyenne comme facteur associe au develeppement du tourisme durable: le cas de la Ville d'Ibague (Colombie)}

Résumé. Quand on s'approche du développement touristique dès la perspective de la durabilité, surtout dès la dimension sociale, la dynamique de la participation citoyenne joue un rôle clé. Ce document est soutenu par une étude de cas qui étudie la participation des citoyens, étant la communauté un facteur associé au développement du tourisme durable dans la ville. Les résultats ont été obtenus par une technique d'analyse de contenu aux informations recueillies par le biais de sondages. Ces résultats reflètent des positions subjectives qui imprègnent les problèmes de participation. Les considérations finales présentent un diagramme iceberg construit sur la base de l'existence d'échecs empêchant la consolidation d'une offerte et vocation touristique dans la ville d'Ibagué. Sur la base des modèles mentaux identifiés, une boucle de rétroaction entre les partis politiques et les citoyens est signalée. Cela entrave la participation et prend sa source dans le débat sur l'importance du développement local.

Mots Clès: participation citoyenne; tourisme durable; développement; politique publique; municipalité.

Cómo citar. Murcia García, C., Ramírez-Casallas, J.F. y Valderrama Riveros, O.C. (2020): La participación ciudadana, factor asociado al desarrollo del turismo sostenible: caso ciudad de Ibagué (Colombia). Anales de Geografía de la Universidad Complutense, 40(1), 135-158.

Sumario. 1. Introducción. 2. Ibagué como como destino turístico y ciudad sostenible. 3. Objetivo y Metodología. 3.1 Población y Muestra. 3.2. Instrumentos y criterios de análisis. 4. Dimensión de resultados. 4.1. Análisis de resultados cuestionario sobre participación (enfoque analítico). 4.2 Representación de los datos según modelo iceberg (enfoque sistémico). 5. Conclusiones y reflexiones finales. 6. Referencias bibliográficas.

\section{Introducción}

Ibagué es un municipio ${ }^{4}$, capital del departamento (Congreso de la República de Colombia, 1991:art. 298) del Tolima (Colombia), fundada en el año 1.550 por el capitán español Andrés López de Galarza, lo que la hace una de las ciudades más antiguas de América. Con un importante patrimonio cultural localizado en su

${ }^{4}$ De acuerdo con el artículo 311 de la actual Constitución Política de Colombia y la Ley 136 de Junio 2 de 1994, es la entidad territorial fundamental de la división político-administrativa del Estado, con autonomía política, fiscal y administrativa dentro de los límites que le señalen la Constitución y las leyes de la República. Sus objetivos son la eficiente prestación de los servicios públicos a su cargo, la construcción de las obras que demande el progreso local, la ordenación de su territorio, la promoción de la participación comunitaria en la gestión de sus intereses y el mejoramiento social y cultural de sus habitantes. 
cabecera municipal y un rico patrimonio natural distribuido en sus diecisiete (17) corregimientos. Se encuentra a una altitud de 1.285 m.s.n.m., con una superficie total de $1.439 \mathrm{~km} 2$; según el Centro de Información Municipal para la Planeación Participativa (CIMPP de Ibagué, 2019), de ellos $43,18 \mathrm{~km}^{2}$ en la actualidad de zona urbana, con una expansión urbana proyectada de $13,4 \mathrm{~km}^{2}$. Hace parte del Parque Nacional Natural Los Nevados, donde nacen las principales fuentes hídricas (Cortolima, 2010).

Con base en esta riqueza, descrita primariamente, la administración municipal ha planteado como meta una Ibagué sostenible para el año 2037 (Alcaldía de Ibagué, 2018), y ha sido finalista en el año 2018 del Desafío de Ciudades, concurso organizado por Wold Wildlife Fund. Esta formulación, en el marco de los atributos que le son reconocidos constitucionalmente (Congreso de la República de Colombia, 1991:art. 311), implica articular responsabilidad y solidaridad comunitaria, considerándose la comunidad como agente del desarrollo. Si se tienen en cuenta las teorías y las aplicaciones de Butler que entre otros aspectos precisa que los agentes del destino provocan los efectos locales como renovación, rejuvenecimiento entre otros (tesis citada por Soares et al. 2015), entonces el papel de la comunidad es clave en el momento de pensar en proyectos colectivos, en la solidez cultural, en el cuidado ambiental en un marco de sostenibilidad.

La inclusión de las comunidades es legítima en el estado colombiano, como expresión del principio general de participación ciudadana (Congreso de la República de Colombia, 1991:art. 103). Por lo tanto, de acuerdo a las atribuciones que posee la administración municipal, esta puede tomar diversas formas, además de los mecanismos que se resaltan en la Ley, como son:

“(...) regula la iniciativa popular legislativa y normativa; el referendo; la consulta Popular, del orden nacional, departamental, distrital, municipal y local; la revocatoria del mandato; el plebiscito y el cabildo abierto (...) La regulación de estos mecanismos no impedirá el desarrollo de otras formas de participación ciudadana en la vida política, económica, social, cultural, universitaria, sindical o gremial del país ni el ejercicio de otros derechos políticos no mencionados en esta ley" (Congreso de la República de Colombia, Ley 134, 1994, Art.1).

En el caso especial de Ibagué, teniendo en cuenta que gran parte de la superficie es rural $\left(1.380 \mathrm{~km}^{2}\right.$ aprox.), ha sido elección de la administración municipal poner en práctica el Turismo Rural Comunitario $(\mathrm{TRC})^{5}$, entendiendo que la TRC es la

${ }^{5}$ El Ministerio de Comercio, Industria y Turismo desde el Viceministerio de Turismo, ha definido los lineamientos para el desarrollo del Turismo Comunitario en Colombia, enmarcados en el compromiso de fortalecer la competitividad y el emprendimiento de la población rural, campesina, indígena, mestiza o afrodescendiente, con el objeto de contribuir a mejorar la calidad de vida, el entendimiento entre las comunidades y proveer de una 
actividad turística que tienen por objeto la estadía en comunidades locales ubicadas en el medio rural organizadas alrededor de la prestación de servicios turísticos en beneficio de la comunidad. El TRC supone la búsqueda por parte del turista de elementos históricos, culturales, medioambientales y autóctonos de dichas comunidades (CODESPA, 2013:11)

Se consolida así como una manera organizada y profesional de explotar el patrimonio, ya que el turismo rural se constituye en el principal motor de desarrollo de las zonas rurales porque responde a una demanda real, contribuye a la salvaguarda del patrimonio a la vez que sirve de activo económico, creando empleos complementarios y alternativos a la agricultura (Yubero Bernabé y Hernández, 2016:176), relevantes como forma de solución a las desigualdades, en un escenario de postconflicto como el que vive el país (Segrelles, 2018).

En este marco, el turismo presenta rasgos de desarrollo importante en la medida que ha sido implementada esta política pública, sin embargo, presenta demora en consolidarse como industria turística en el marco de la sostenibilidad. Al respecto, a pesar de contar con el Cañón del Combeima (espacio natural que tiene en su cabecera el Nevado del Tolima), y ser conocida como la Capital Musical de Colombia (Concejo Municipal de Ibagué, 2014) por su cultura y actividad musical, entre otros, aún no se menciona entre los "destinos oficiales" del Gobierno Nacional por carecer de un producto competitivo para el mercado internacional (FONTUR, 2015). De forma consistente, la búsqueda documental reveló la ausencia de un inventario turístico debidamente actualizado y valorado; además [...] "se han identificado una serie de falencias que no le han permitido a la ciudad consolidar su oferta turística y su vocación como destino turístico competitivo y sustentable." (Alcaldía de Ibagué, 2016:114).

Es precisamente esta demora la que se considera el problema marco de este trabajo de investigación. En concreto, ¿cómo se relaciona la participación ciudadana con el desarrollo del turismo sostenible? Comprender este problema en el caso de la ciudad de Ibagué, aporta información valiosa para comprender, intervenir y afectar de manera positiva dicho desarrollo (Liévano Martínez y Londoño, 2012:46).

En un plano teórico, esta pregunta puede resolverse desde distintas perspectivas. En particular, los autores consideran que el turismo sostenible en el caso de la ciudad de Ibagué puede concebirse como una realidad social que posee dimensiones objetivas y subjetivas (Ramírez-Casallas, 2010). A lo que se suma de manera general que se consideran importantes la historia, la cultura y la política, como preceptos de la geografía humana (Caballero-Miguez, 2009), relevantes en la comprensión local de la realidad social y su evolución. La síntesis de las anteriores premisas hace posible aceptar una concepción institucional (organizaciones sociales, empresas, instituciones educativas, etc.) en la que:

alternativa productiva que permite la protección del medio ambiente y el empoderamiento del patrimonio cultural. 
"De este modo, la comprensión del papel de las instituciones en la geografía humana ha asumido la relevancia de atender las relaciones entre las reglas subjetivas del individuo y las reglas interpersonales que configuran las instituciones. De este modo se clarifica cómo las instituciones afectan el comportamiento humano, cómo influyen en la concepción institucional del espacio y cómo establecen vínculos con los individuos de su correspondiente entorno político-social" (Caballero-Miguez, 2009:23).

En el marco de estos principios generales, y con la intención de aportar una mejor comprensión del papel de la participación ciudadana en el desarrollo del turismo sostenible, se ha considerado útil y consistente la representación tipo iceberg, propuesta por Peter Senge et al. (2009:182), como una forma de organizar los datos sobre este caso particular, y avanzar una explicación sistémica sobre la realidad.

Consideran Peter Senge et al. (2009) que existen diversas maneras de explicar la realidad. La referencia a los hechos apenas son la punta de un iceberg, son la expresión visible e inmediata de la realidad. La búsqueda de patrones y tendencias busca poner estos hechos en un marco evolutivo, a lo largo del tiempo. De esta manera se puede cuestionar si los hechos identificados son relevantes o no. Profundizando la explicación de la realidad, es posible identificar las estructuras o fuerzas sistemáticas que explican el surgimiento y prevalencia de ciertos patrones y tendencias. En la base de la realidad se encuentran los modelos mentales, los que explican nuestras creencias más arraigadas.

En estas condiciones se acepta que:

"Desde el punto de vista del observador científico, las instituciones son regularidades compartidas de comportamiento o rutinas de una población; desde un punto de vista interno, las instituciones no son más que los modelos mentales o soluciones compartidas a problemas recurrentes de interacción social situadas en la mente de la gente" (Caballero-Miguez, 2009:18).

En consecuencia, es viable formular la pregunta de interés para abordarla desde las diversas formas de explicación que Senge et al. (2009) proponen.

\section{Ibagué como como destino turístico y ciudad sostenible}

El departamento de Tolima ofrece atractivos turísticos desde el punto de vista natural, cultural y científico. En ecoturismo son de gran importancia los parques nacionales naturales de Los Nevados y Las Hermosas. Un gran atractivo lo constituyen las fiestas de San Pedro y San Juan, en El Espinal, y las fiestas patronales de los municipios, así como el festival folclórico de Ibagué, la capital del departamnento. Esta ha sido reconocida como la ciudad musical de Colombia, título dado por personajes que la visitaron en el siglo XIX, maravillados con el ambiente musical que existía en la ciudad y fue así como en 1886 el Conde de Gabriac, impresionado con la ciudad, escribió un artículo denominado Ibagué, Ciudad Musical. Es 
frecuente encontrar menciones que destacan que las noches en la capital musical eran animadas con bundes, bambucos y pasillos desgarrados de las cuerdas, tiples y guitarras de sus habitantes, dotados de una gran destreza musical (Fondo de Promoción Turística del Tolima, 2012:20). Ibagué tiene su propia biografía y su propia configuración histórica, urbana, política y cultural.

Respecto a la infraestructura que permite la recepción de visitantes, Ibagué presenta buena infraestructura hotelera, restaurantes y centros de convenciones, permitiéndole el desarrollo de diferentes eventos culturales, comerciales, profesionales entre otros. La cercanía con el cañón del río Combeima la conecta con el Nevado del Tolima y al Parque Natural de los Nevados. La zona del Totumo ofrece recreación y esparcimiento (Cortolima, 2012:136).

Figura 1. Localización geográfica de la ciudad de Ibagué en Colombia.

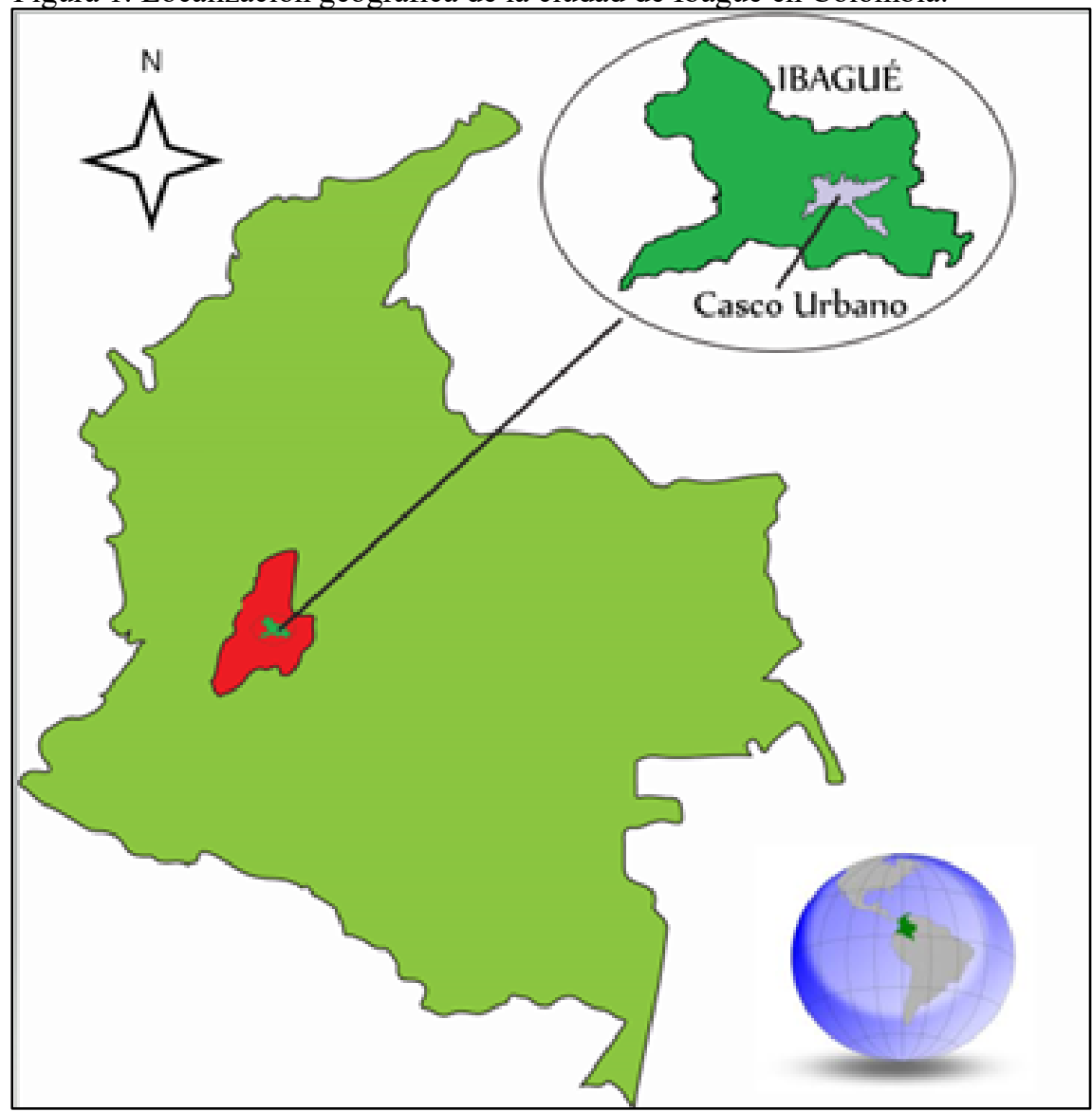

Fuente: Elaboración propia. 
En relación con el planeamiento de la ciudad, el Plan de Ordenamiento Territorial (Alcaldía de Ibagué, 2014), establece el modelo territorial de la ciudad de Ibagué, con una ocupación donde resalta nodos de importancia turística: el cañón del Combeima, sector del Salado y Sector del Totumo, cada uno con su propia vocación. Al interior de la ciudad cuenta con una Área Patrimonial, desarrollado alrededor del Panóptico con su área aferente incluyendo el cerro de Pan de Azúcar y la Sexta Brigada; un área ambiental, desarrollada en el predio ocupado por el parque Centenario y por último un área histórica desarrollada alrededor del parque Simón Bolívar, de la Plaza Murillo Toro y entre las calles 10 y 13 que se comporta como estructurante y eje estructural que une dos tensiones entre la Plazoleta de la Música y el Panóptico (Alcaldía de Ibagué, 2014:arts. 8 y 17).

Figura 2. Actividad turística en el municipio de Ibagué: Patrimonio natural activo para visitantes y patrimonio cultural en la zona urbana.

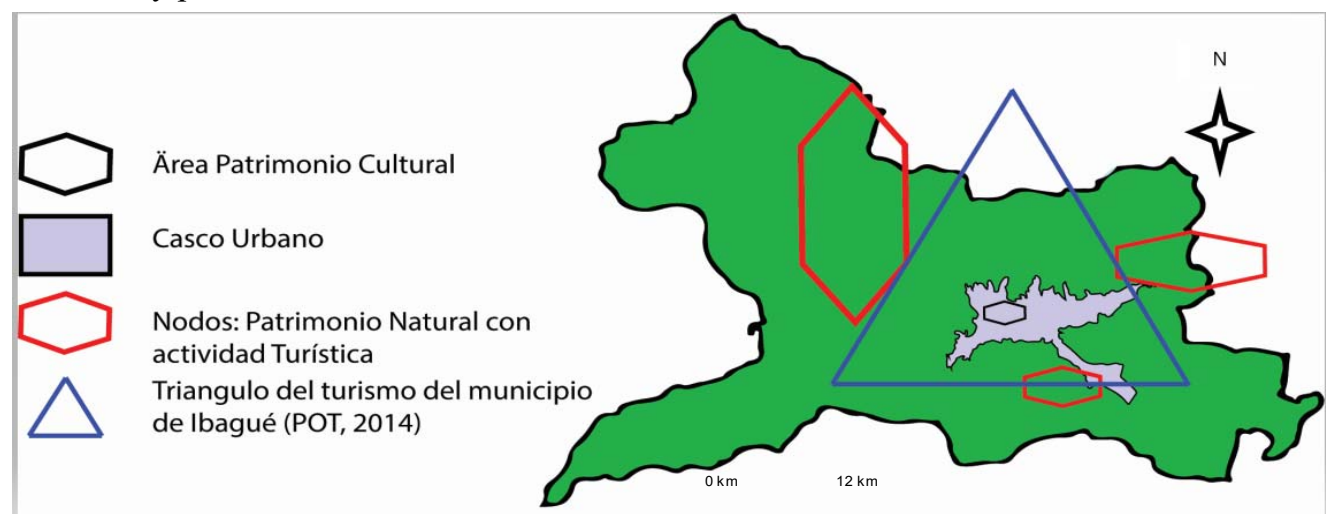

Fuente: Elaboración propia con base en Plan de Ordenamiento Territorial (Alcaldía de Ibagué, 2014).

De igual manera, el modelo de desarrollo de la ciudad proyectado precisa la ciudad como centro regional, invita a la apropiación respetuosa del potencial ambiental y paisajístico de la ciudad, el fortalecimiento de la calidad de vida para toda la población del municipio y la promoción de la productividad y competitividad del territorio de Ibagué (Alcaldía Municipal de Ibagué, 2014:art. 8) desde una perspectiva sostenible (Alcaldía Municipal de Ibagué, 2018).

El Acuerdo 035 de 1990, mediante el cual se implementa el Estatuto Urbano de Ibagué, define 13 Comunas para la zona urbana que comprende 516 barrios aproximadamente, mientras el Acuerdo 037 de 1992 designa 17 Corregimientos para la zona rural que comprende actualmente 144 asociaciones veredales, pero reconocidas por Acuerdo Municipal son apenas 137 veredas (Cortolima, 2010:48)

Profundizando en el patrimonio natural, "se identifican numerosas áreas de especial importancia ambiental, al constituirse en fuente potencial de riqueza y en imagen del Municipio." (Cortolima, 2010:159) El área rural comprendida por los diecisiete (17) corregimientos, muy cercanos al triangulo de turismo del municipio, 
constituyen un potencial para el desarrollo del turismo rural comunitario (TRC), en primer lugar el Parque Nacional de los Nevados, "representa una oportunidad de generación de ingresos y de desarrollo para comunidades rurales ubicadas cerca de atractivos turísticos y que aún no se benefician económicamente de los visitantes a la zona". (CODESPA, 2013:9).

En relación con la dimensión sostenible de la ciudad, a los anteriores atractivos se suman proyectos de adecuación de vías para promover la ciclomovilidad en la ciudad, el uso de la energía solar como fuente energética del alumbrado público en las ciclorutas, la planeada adquisición (en progreso) de 4 mil hectáreas en los zonas abastecedoras de agua, zonas estas en las que la Alcaldía espera sembrar 2.5 millones de árboles (Caracol Radio Ibagué, 2018).

\section{Objetivo y Metodología}

Con base en las premisas teóricas arriba expuestas, se considera que el estudio de caso (Stake, 1999) es el más apropiado para investigar lo que sucede con la participación ciudadana en el desarrollo del turismo sostenible en la ciudad de Ibagué. Con la representación tipo iceberg se busca aportar una comprensión del fenómeno que no necesariamente se considera generalizable a otras regiones; por lo que la producción de ciencia regional se considera fundamental en la mejora de la participación para la planeación del turismo sostenible en la ciudad.

Por otro lado, aunque existen estudios de caso en los que se aborda la construcción de sostenibilidad local desde la perspectiva de las zonas periurbanas (Zulaica y Tomadoni, 2015); desde una perspectiva institucional, al ser relevantes los modelos mentales de las personas, surge como cuestión complementaria la pregunta por la forma en que las instituciones ayudan a promover el desarrollo local. Como parte de una institución universitaria, dichos interrogantes se han abordado desde el estudio de las prácticas profesionales y las interacciones que mantienen con otras organizaciones de la región (Ramírez-Casallas, Ramírez-Arcila, 2018), o sobre la forma en que dichos modelos se afectan en la construcción de emprendimiento (Murcia et al., 2015; Murcia, et al., 2017), pero a pesar de ello, se considera que este estudio aporta una visión diferente y complementaria sobre el papel de dichos modelos en relación con las organizaciones locales y la forma en que los ciudadanos participan en la consolidación de un turismo sostenible.

\subsection{Población y Muestra}

La muestra, de 384 personas de una población total de $558.815^{6}$ que posee la ciudad de Ibagué, corresponde en su mayor parte (81 aprox.\%) a población estudiantil

\footnotetext{
${ }^{6}$ Información estadística del DANE, año 2016.
} 
universitaria (tabla 1). Y esto fue así porque este tipo de población estuvo dispuesta, sin mayores problemas, a resolver las preguntas ${ }^{7}$. Por las condiciones anteriores, esta muestra se ha considerado intencionada, y el principal criterio de asunción ha sido el que será precisamente este sector de la población del que se espera, por su nivel formativo y su injerencia en las instituciones del territorio, que puedan cambiar las rutinas o comportamientos institucionales relacionados con el turismo sostenible en la ciudad. Comprender cómo conciben la participación ciudadana es fundamental para entender esta como factor asociado a la evolución del turismo sostenible, en especial para comprender las causas profundas que explican sus avances y retrocesos.

Para realizar la clasificación de las personas encuestadas, se usa su pertenencia a uno de los seis estratos (1 mínimo, 6 máximo), en los que se puede ubicar un ciudadano colombiano de acuerdo con los servicios públicos de los que goza (Congreso de la República de Colombia, 1994). Este modelo, cuestionado desde diversas perspectivas, parte de considerar que el nivel de dotación de servicios es un indicador de los ingresos actuales de una familia (v.g Ortega-Montes, et al., 2008).

Tabla 1. Perfil sociodemográfico de la muestra.

\begin{tabular}{l|c|c|}
\hline Variable & Frecuencia & Porcentaje \\
Estudiantes & 311 & $80,9 \%$ \\
Ciudadanos & 73 & $19,1 \%$ \\
*Con edades entre 19 y 54 años. & & \\
\hline Estratos & 46 & $12 \%$ \\
Bajo (estratos 1 y 2) & 138 & $36 \%$ \\
Medio bajo ( estrato 3) & 188 & $49 \%$ \\
Medio medio (estrato 4) & 12 & $3 \%$ \\
Alto (estratos 5 y 6) & & \\
\hline
\end{tabular}

Fuente: Elaboración propia.

Aquí se comparte el cuestionamiento a dicha premisa, pero sí se toma como indicador que pertenecer a un estrato más alto se relaciona positivamente con la riqueza cultural a la que pueden acceder los integrantes de una familia; lo que significa que pertenecer a un estrato más alto ofrece, en general, ventajas posteriores en términos de movilidad social futura, como es el caso de la calidad educativa medida según pruebas estandarizadas en todos los niveles escolares (Chica, Galvis y Ramírez, 2010).

${ }^{7}$ Este comportamiento, al acceder a responder la encuesta, aporta una primera condición favorable de los estudiantes universitarios hacia la participación, exponiendo sus visiones sobre el turismo como problemática. 


\subsection{Instrumentos y criterios de análisis}

Como instrumento se ha optado por un cuestionario, conformado por ocho (8) preguntas (tabla 2); siete (7) tomadas de manera parcial del documento ¿Qué ha pasado con la participación ciudadana en Colombia ${ }^{8}$, algunas con pequeñas modificaciones y una (1) aportada en el presente estudio para conocer la posición de los encuestados frente al tema de turismo y paz.

Tabla 2. Cuestionario sobre participación ciudadana.

\begin{tabular}{|c|c|}
\hline $\begin{array}{c}\text { Número de la } \\
\text { Pregunta }\end{array}$ & \multicolumn{1}{c|}{ Texto de la pregunta } \\
$\mathbf{1}$ & $\begin{array}{l}\text { ¿Qué lo motiva para intervenir en instancias de participación? } \\
\text { ¿Estaría usted dispuesto(a) a trabajar con sus vecinos en la solución de los } \\
\text { problemas de su barrio o vereda? } \\
\text { ¿Qué razones tiene para no lanzarse como candidato(a) a un organismo de } \\
\text { participación ciudadana? }\end{array}$ \\
$\mathbf{3}$ & $\begin{array}{l}\text { ¿Qué obstáculos observa que afectan la participación ciudadana? } \\
\text { ¿Cuáles son las razones por las que no está dispuesto(a) a cooperar en la solución } \\
\text { de problemas de su vecindario? } \\
\mathbf{5}\end{array}$ \\
$\mathbf{6}$ & $\begin{array}{l}\text { ¿Los partidos políticos y sus dirigentes apoyan la participación ciudadana? } \\
\text { ciudadana? }\end{array}$ \\
$\mathbf{7}$ & $\begin{array}{l}\text { Relacione el ítem que considere con máxima afinidad entre turismo, paz y } \\
\text { convivencia en Ibagué. }\end{array}$ \\
\hline
\end{tabular}

Fuente: Las primeras siete preguntas fueron adaptadas de Velázquez y González (2003).

La información que ha sido recopilada se analiza para cada pregunta, usando como técnica el análisis de contenido (Piñuel Raigada, 2002). En este proceso, las proposiciones obtenidas para cada una de las respuestas, se han agrupado en proposiciones prototípicas que recogen el sentido de las ideas expuestas por cada persona en el cuestionario. En primer lugar, se discute y analiza la información pregunta a pregunta (enfoque analítico); en segundo lugar, con base en la representación de iceberg, se establece al final una representación de síntesis (figura 3) que tiene como propósito aportar una visión sistémica sobre la participación ciudadana como factor asociado al turismo sostenible en el caso específico de la ciudad de Ibagué.

\footnotetext{
${ }^{8}$ Estudio realizado por Fabio Velázquez C. y Esperanza Gonzales R., con un grupo promotor conformado por Corporaciones, Fundaciones, Universidad de los Andes; editado por la Fundación Corona, autorizando la reproducción parcial o total de la obra.
} 


\section{Discusión de resultados}

\subsection{Análisis de resultados cuestionario sobre participación (enfoque analítico)}

La motivación alude a dos palabras claves: a) Motivos o energía interna que nos impele a una determinada acción; b) Motor o aquello que nos mueve al logro de una finalidad (Gan y Triginé, 2012:240). La mayor tendencia que motiva a servir a la comunidad se observa en el estrato alto con un $75 \%$, seguido del bajo con un $70 \%$. En el contexto de respuestas, este ítem está por encima del deseo de negociar con la administración, buscar beneficios familiares y obtener prestigio. Refleja en la población encuestada un alto grado de solidaridad en el momento que expresan su deseo de servir a la comunidad.

Tabla 4. Descripción porcentual de los resultados obtenidos a la pregunta 1 .

\begin{tabular}{|c|c|c|c|c|c|c|c|c|}
\hline \multirow{2}{*}{$\begin{array}{c}\text { P1: ¿Qué lo motiva para } \\
\text { intervenir en instancias de } \\
\text { participación? }\end{array}$} & \multicolumn{8}{|c|}{ Estratos } \\
\hline & Bajo & $\mathbf{N}$ & $\begin{array}{l}\text { Medio- } \\
\text { bajo }\end{array}$ & $\mathbf{N}$ & $\begin{array}{l}\text { Medio } \\
\text { med. }\end{array}$ & $\mathbf{N}$ & Alto & $\mathbf{N}$ \\
\hline Me gusta servir a la comunidad & $70 \%$ & 32 & $63 \%$ & 87 & $62 \%$ & 117 & $75 \%$ & 9 \\
\hline $\begin{array}{l}\text { Son una oportunidad para } \\
\text { negociar con la administración } \\
\text { municipal }\end{array}$ & $4 \%$ & 2 & $9 \%$ & 13 & $13 \%$ & 25 & $17 \%$ & 2 \\
\hline $\begin{array}{l}\text { Puedo obtener algún beneficio } \\
\text { personal o para mi familia }\end{array}$ & $9 \%$ & 4 & $14 \%$ & 19 & $15 \%$ & 28 & & \\
\hline $\begin{array}{l}\text { Participando en esos organismos } \\
\text { gano prestigio }\end{array}$ & $6 \%$ & 3 & $4 \%$ & 5 & $1 \%$ & 2 & & \\
\hline Otra & $11 \%$ & 5 & $10 \%$ & 14 & $9 \%$ & 16 & $8 \%$ & 1 \\
\hline Total & $100 \%$ & 46 & $100 \%$ & 138 & $100 \%$ & 188 & $100 \%$ & 12 \\
\hline
\end{tabular}

Fuente: Elaboración propia

La motivación para la participación de los ciudadanos en el desarrollo local, es relevante en estos periodos en donde las realidades sociales presentan vastas perspectivas que demandan soluciones inmediatas, requiriéndose de la unión y la solidaridad, el trabajo autogestionario de la comunidad para hacerle frente a las soluciones planteadas desde la base social.

La "participación ciudadana" amplía así su ámbito de significación y pasa a referirse a una realidad más extensa y profunda, que aspira a influenciar todo tipo de decisiones y acciones que afectan a "la gente", provengan de donde provengan y se den donde se den. Son formas de participación más maduras y autónomas, menos dependientes de la implicación de las autoridades públicas para iniciarse y, por tanto, también más emancipadas del control gubernamental. (Prieto-Martín y RamírezAlujas, 2014:68-69).

El deseo de servir a la comunidad involucra la energía interna y el motor que mueve a la persona al compromiso colectivo, factor determinante y requerido para el 
desarrollo del turismo desde las propias propuestas que se incluyan en el sistema de planeación y presupuesto participativo en la ciudad de Ibagué.

Tabla 5. Descripción porcentual de los resultados obtenidos a la pregunta 2.

\begin{tabular}{|c|c|c|c|c|c|c|c|c|}
\hline $\begin{array}{c}\text { P2: ¿Estaría usted } \\
\text { dispuesto(a) a trabajar } \\
\begin{array}{c}\text { con sus vecinos en la } \\
\text { solución de los problemas } \\
\text { de su barrio o vereda? }\end{array}\end{array}$ & Bajo & $\mathbf{N}$ & $\begin{array}{c}\text { Medio } \\
\text { bajo }\end{array}$ & $\mathbf{N}$ & $\begin{array}{c}\text { Medio - } \\
\text { medio. }\end{array}$ & $\mathbf{N}$ & Alto & N \\
\cline { 2 - 9 } Sí & $76 \%$ & 35 & $88 \%$ & 121 & $79 \%$ & 149 & $58 \%$ & 7 \\
No & $24 \%$ & 11 & $12 \%$ & 17 & $21 \%$ & 39 & $42 \%$ & 5 \\
Total & $100 \%$ & 46 & $100 \%$ & 138 & $100 \%$ & 188 & $100 \%$ & 12 \\
\hline
\end{tabular}

Fuente: Elaboración propia.

El trabajo colectivo permite el desarrollo y la solución de problemas locales, situación favorecida con la respuesta que muestra un porcentaje promedio de $81 \%$ entre los estratos bajo, medio bajo y medio medio, mientras que un $58 \%$ en el estrato alto. Se debe tener en cuenta que todos los ciudadanos tienen tareas por cumplir de acuerdo a sus capacidades sin olvidar que existen complejidades representadas en intereses de los grupos que representan, costumbres, cultura y conflictos (Álvarez et al., 2014).

Tabla 6. Descripción porcentual de los resultados obtenidos a la pregunta 3.

\begin{tabular}{|c|c|c|c|c|c|c|c|c|}
\hline \multirow{2}{*}{$\begin{array}{l}\text { P3: ¿Qué razones tiene } \\
\text { para no lanzarse como } \\
\text { candidato(a) a un } \\
\text { organismo de } \\
\text { participación ciudadana? }\end{array}$} & \multicolumn{8}{|c|}{ Estratos } \\
\hline & Bajo & $\mathbf{N}$ & $\begin{array}{c}\text { Medio } \\
\text { bajo }\end{array}$ & $\mathbf{N}$ & $\begin{array}{l}\text { Medio- } \\
\text { medio }\end{array}$ & $\mathbf{N}$ & Alto & $\mathbf{N}$ \\
\hline $\begin{array}{l}\text { Porque no tengo } \\
\text { condiciones }\end{array}$ & $17 \%$ & 8 & $11 \%$ & 15 & $7 \%$ & 14 & $8 \%$ & 1 \\
\hline Porque no me gusta & $33 \%$ & 15 & $37 \%$ & 51 & $36 \%$ & 67 & $43 \%$ & 5 \\
\hline $\begin{array}{l}\text { Porque yo no entiendo los } \\
\text { asuntos de la política }\end{array}$ & $11 \%$ & 5 & $15 \%$ & 21 & $12 \%$ & 22 & $8 \%$ & 1 \\
\hline $\begin{array}{l}\text { Porque esos organismos } \\
\text { son nidos de politiquería y } \\
\text { corrupción }\end{array}$ & $9 \%$ & 4 & $18 \%$ & 24 & $16 \%$ & 31 & $25 \%$ & 3 \\
\hline Porque no soy líder & $2 \%$ & 1 & $7 \%$ & 10 & $5 \%$ & 9 & $8 \%$ & 1 \\
\hline $\begin{array}{l}\text { Porque esos organismos no } \\
\text { ayudan a resolver los } \\
\text { problemas }\end{array}$ & $4 \%$ & 2 & $1 \%$ & 2 & $3 \%$ & 5 & & \\
\hline $\begin{array}{l}\text { Porque esos organismos } \\
\text { son pura burocracia }\end{array}$ & $11 \%$ & 5 & $2 \%$ & 3 & $9 \%$ & 17 & & \\
\hline Otra & $13 \%$ & 6 & $9 \%$ & 12 & $12 \%$ & 23 & $8 \%$ & 1 \\
\hline Total & $100 \%$ & 46 & $100 \%$ & 138 & $100 \%$ & 188 & $100 \%$ & 12 \\
\hline
\end{tabular}

Fuente: Elaboración propia. 
Abundando en lo anterior se incursiona en la cultura ciudadana, importante para darle solidez al trabajo colectivo, sin una cultura que permita entender e involucrar la comunidad es difícil propender por el desarrollo local, que en este caso es el turismo sostenible, el cual demanda de una cultura propia. Al respecto,

“(...) el estudio de las individualidades populares. v su característica mesosociológica. se desprende de estos tres factores: (1) su autonomía cultural relativa permite comprender que si sus miembros comparten orientaciones culturales de más o menos fuerte especificidad grupal. esto no les impide compartir, al mismo tiempo, elementos de la cultura mainstream: (2) la autonomía cultural relativa de las orientaciones normativas de este grupo social deben ser siempre interpretadas desde su naturaleza" (Araujo y Martuccelli, 2015:90).

A diferencia de los demás ítem, los encuestados consideran como razón principal para no lanzarse como candidato a un organismo de participación ciudadana es que simplemente no les gusta. La respuesta en este ítem es la más alta, situándose en un promedio de $37 \%$, seguido del porque esos organismos son nidos de politiquería y corrupción, en un 17\%; no entiende asuntos de política con un $11 \%$ y no tiene condiciones en un $10 \%$. Es preocupante la respuesta al denotar razones sentidas por el colectivo que pese al deseo de trabajar por la comunidad y desarrollar trabajo con los vecinos, su liderazgo se vea opacada por factores ocultos que atentan posiblemente contra el factor confianza en los ciudadanos, que puede ser la falta de competencias, la corrupción y politiquería que rodean esos organismos, las amenazas según respuestas de entrevistas grupales.(...) "si la misión de los actores e instituciones políticas es representar a los ciudadanos, la evaluación de los primeros por parte de estos últimos debe girar en torno de la calidad de la representación" (Del Tronco, 2013,59).

En respuestas anteriores, el colectivo manifiesta una importante fuerza impulsora para trabajar con la comunidad, pero para representar una comunidad, esa fuerza se disminuye en el momento de tomar visibilidad en la comunidad, de ser líder o protagonista. Esta ausencia de deseo se combina con el factor confianza en las instituciones públicas; situación que afecta el turismo en el momento de impulsar propuestas de desarrollo.

Son tres obstáculos que afectan la participación ciudadana, en su orden se encuentra la falta de información, seguido de la desconfianza de la gente hacia los demás y el desconociendo de los derechos por parte de la gente. El primer obstáculo más sentido en el estrato medio en un 53\% y en el alto en un 50\%. Este panorama no es propicio ni para fomentar la cultura ciudadana ni para establecer las bases para la participación en el desarrollo del turismo, razón que puede ayudar a explicar en parte el estado estacionario actual del mismo y el motivo de ausencia de empresas turísticas comunitarias. 
Tabla 7. Descripción porcentual de los resultados obtenidos a la pregunta 4.

\begin{tabular}{|c|c|c|c|c|c|c|c|c|}
\hline \multirow{2}{*}{$\begin{array}{c}\text { P4: ¿Qué obstáculos observa que } \\
\text { afectan la participación } \\
\text { ciudadana? }\end{array}$} & \multicolumn{8}{|c|}{ Estratos } \\
\hline & Bajo & $\mathbf{N}$ & $\begin{array}{l}\text { Medio } \\
\text { bajo }\end{array}$ & $\mathbf{N}$ & $\begin{array}{l}\text { Medio } \\
\text { medio }\end{array}$ & $\mathbf{N}$ & Alto & $\mathbf{N}$ \\
\hline La falta de información & $46 \%$ & 21 & $53 \%$ & 73 & $37 \%$ & 70 & $50 \%$ & 6 \\
\hline $\begin{array}{l}\text { La desconfianza de la gente hacia } \\
\text { los demás }\end{array}$ & $17 \%$ & 8 & $12 \%$ & 16 & $19 \%$ & 36 & $8 \%$ & 1 \\
\hline $\begin{array}{l}\text { El desconocimiento de los derechos } \\
\text { por parte de la gente }\end{array}$ & $15 \%$ & 7 & $14 \%$ & 19 & $18 \%$ & 34 & $17 \%$ & 2 \\
\hline La falta de voluntad de los políticos & $13 \%$ & 6 & $8 \%$ & 11 & $5 \%$ & 9 & $8 \%$ & 1 \\
\hline La falta de conciencia de la gente & & & $8 \%$ & 11 & $13 \%$ & 25 & $8 \%$ & 1 \\
\hline La falta de tiempo & & & $1 \%$ & 2 & $1 \%$ & 2 & & \\
\hline El conflicto armado & & & $0,7 \%$ & 1 & $1 \%$ & 2 & & \\
\hline $\begin{array}{l}\mathrm{La} \text { inexistencia de mecanismos } \\
\text { adecuados }\end{array}$ & & & $0,7 \%$ & 1 & $2 \%$ & 4 & & \\
\hline $\begin{array}{l}\text { La legislación muy rígida y } \\
\text { exigente }\end{array}$ & & & & & $1 \%$ & 1 & & \\
\hline Otro & $9 \%$ & 4 & $2,6 \%$ & 4 & $3 \%$ & 5 & $9 \%$ & 1 \\
\hline Total & $100 \%$ & 46 & $100 \%$ & 138 & $100 \%$ & 188 & $100 \%$ & 12 \\
\hline
\end{tabular}

Fuente: Elaboración propia

La participación ciudadana consiste en las actividades que, interactuando ante y con el Estado, buscan transformarlo para incidir en el diseño, definición y programación de las políticas públicas. Estas pueden abarcar desde la legitimación y legalización de nuevos derechos positivos, pasando por el establecimiento de mecanismos para organizar la vida democrática, hasta la planeación de programas y su ejecución. (Aguirre Sala, 2014:213)

Tabla 8. Descripción porcentual de los resultados obtenidos a la pregunta 5.

\begin{tabular}{|c|c|c|c|c|c|c|c|c|}
\hline \multirow{2}{*}{$\begin{array}{l}\text { P5: ¿Cuáles son las razones por } \\
\text { las que no está dispuesto(a) a } \\
\text { cooperar en la solución de pro- } \\
\text { blemas de su vecindario? }\end{array}$} & \multicolumn{8}{|c|}{ Estratos } \\
\hline & Bajo & $\mathbf{N}$ & $\begin{array}{l}\text { Medio } \\
\text { bajo }\end{array}$ & $\mathbf{N}$ & $\begin{array}{l}\text { Medio } \\
\text { med. }\end{array}$ & $\mathbf{N}$ & Alto & $\mathbf{N}$ \\
\hline No tengo tiempo ni recursos & $22 \%$ & 10 & $23 \%$ & 32 & $17 \%$ & 32 & $17 \%$ & 2 \\
\hline $\begin{array}{l}\text { No me gusta participar en las cosas } \\
\text { del barrio o la vereda }\end{array}$ & $4 \%$ & 2 & $2 \%$ & 3 & $3 \%$ & 6 & $8 \%$ & 1 \\
\hline $\begin{array}{l}\text { En el vecindario hay mucho conflic- } \\
\text { to y poca colaboración }\end{array}$ & $13 \%$ & 6 & $19 \%$ & 26 & $19 \%$ & 35 & $17 \%$ & 2 \\
\hline $\begin{array}{l}\text { Hay gente que monopoliza las } \\
\text { organizaciones y no deja participar }\end{array}$ & $9 \%$ & 4 & $14 \%$ & 20 & $14 \%$ & 26 & & \\
\hline $\begin{array}{l}\text { No confío en la gente de mi barrio o } \\
\text { vereda }\end{array}$ & & & $4 \%$ & 5 & $2 \%$ & 3 & $17 \%$ & 2 \\
\hline No tengo ningún motivo en especial & $20 \%$ & 9 & $18 \%$ & 25 & $28 \%$ & 52 & $17 \%$ & 2 \\
\hline $\begin{array}{l}\text { Para eso están la Junta de Acción } \\
\text { Comunal y otras organizaciones }\end{array}$ & $9 \%$ & 4 & $6 \%$ & 7 & $7 \%$ & 13 & $16 \%$ & 2 \\
\hline Otras & $24 \%$ & 11 & $14 \%$ & 20 & $10 \%$ & 21 & $8 \%$ & 1 \\
\hline Total & $100 \%$ & 46 & $100 \%$ & 138 & $100 \%$ & 188 & $100 \%$ & 12 \\
\hline
\end{tabular}

Fuente: Elaboración propia 
No existe la cooperación entre vecinos por no tener tiempo ni recursos y por no tener un motivo en especial; lo que se refleja un porcentaje relativamente alto en todos los estratos, con promedio de $20 \%$ y $21 \%$, respectivamente, por encima de ítem conflicto en el vecindario y poca colaboración y que hay gente monopoliza las organizaciones y no deja participar. Se observa un acentuado individualismo acrecentado por las nefastas experiencias en estos organismos que han estado rodeados por el clientelismo y la corrupción. "Esta experiencia, indisociable de una posición común de clase, da paso a una expresión altamente individualizada de la capacidad de sus miembros" (Araujo y Martuccelli, 2015:93).

A simple vista el escenario refleja ausencia de educación en aspectos de participación ciudadana, factor básico para generar confianza; sumado esto al nuevo estilo de vida que absorbe al ciudadano en un ámbito de individualismo, en donde las TIC toman un alto protagonismo.

Tabla 9. Descripción porcentual de los resultados obtenidos a la pregunta 6.

\begin{tabular}{|c|c|c|c|c|c|c|c|c|}
\hline \multirow{2}{*}{$\begin{array}{c}\text { P6: ¿Los partidos políticos y sus } \\
\text { dirigentes apoyan la } \\
\text { participación ciudadana? }\end{array}$} & \multicolumn{8}{|c|}{ Estratos } \\
\hline & Bajo & $\mathbf{N}$ & $\begin{array}{c}\text { Medio } \\
\text { bajo }\end{array}$ & $\mathbf{N}$ & $\begin{array}{l}\text { Medio } \\
\text { medio }\end{array}$ & $\mathbf{N}$ & Alto & $\mathbf{N}$ \\
\hline Sí & $6 \%$ & 3 & $20 \%$ & 27 & $27 \%$ & 50 & $17 \%$ & 2 \\
\hline $\begin{array}{l}\text { No } \\
\text { No sé }\end{array}$ & $\begin{array}{c}43 \% \\
50 \% \\
100 \%\end{array}$ & $\begin{array}{l}20 \\
23 \\
46\end{array}$ & $\begin{array}{c}32 \% \\
48 \% \\
100 \%\end{array}$ & $\begin{array}{c}45 \\
66 \\
138\end{array}$ & $\begin{array}{c}27 \% \\
46 \% \\
100 \%\end{array}$ & $\begin{array}{c}51 \\
87 \\
188\end{array}$ & $\begin{array}{c}41 \% \\
42 \% \\
100 \%\end{array}$ & $\begin{array}{c}5 \\
5 \\
12\end{array}$ \\
\hline
\end{tabular}

Fuente: Elaboración propia.

Los partidos políticos son organizaciones adscritas a una ideología con derecho a participar en los procesos políticos. (...) "Los Partidos y Movimientos Políticos se organizarán democráticamente y tendrán como principios rectores la transparencia, objetividad, moralidad, la equidad de género, y el deber de presentar y divulgar sus programas políticos" (Congreso de la República de Colombia, 1991:art.107). Es preocupante el desconocimiento del papel que desempeñan los partidos políticos, el estrato bajo presenta un índice del $50 \%$ reduciéndose en la medida que avanza el estrato pero sin dejar de ser alarmante, de igual manera, la percepción de que no existe apoyo por parte de éstos para la participación ciudadana representa en el mismo estrato el $43 \%$, resultados que permiten pensar que en los estratos bajos está representada la abstención al voto o la vulnerabilidad en la opción del mismo en el momento de participar en procesos electorales y de actividades comunitarias.

En consecuencia, atendiendo los resultados se puede considerar que el colectivo no cuenta con una clara disciplina del voto, experimenta una pérdida del control político, no entiende el papel de los partidos políticos y no desea involucrarse en actividades colectivas orientadas por los partidos políticos y más los que dirigen la administración pública. 
Tabla 10. Descripción porcentual de los resultados obtenidos a la pregunta 7.

\begin{tabular}{|c|c|c|c|c|c|c|c|c|}
\hline \multirow{2}{*}{$\begin{array}{l}\text { P7: ¿Cuál cree es la } \\
\text { principal razón para que la } \\
\text { alcaldía no apoye la } \\
\text { participación ciudadana? }\end{array}$} & \multicolumn{8}{|c|}{ Estratos } \\
\hline & Bajo & $\mathbf{N}$ & $\begin{array}{c}\text { Medio } \\
\text { bajo }\end{array}$ & $\mathbf{N}$ & $\begin{array}{l}\text { Medio } \\
\text { medio }\end{array}$ & $\mathbf{N}$ & Alto & $\mathbf{N}$ \\
\hline $\begin{array}{l}\text { Porque a los políticos no les } \\
\text { interesa }\end{array}$ & $48 \%$ & 22 & $41 \%$ & 57 & $36 \%$ & 67 & $42 \%$ & 5 \\
\hline $\begin{array}{l}\text { Porque no hay dinero y se lo } \\
\text { robaron }\end{array}$ & $24 \%$ & 11 & $22 \%$ & 30 & $27 \%$ & 50 & $25 \%$ & 3 \\
\hline $\begin{array}{ll}\text { Porque no se entiende la } \\
\text { importancia } \\
\text { participación ciudadana }\end{array}$ & $28 \%$ & 13 & $37 \%$ & 51 & $37 \%$ & 71 & $33 \%$ & 4 \\
\hline Total & $100 \%$ & 46 & $100 \%$ & 138 & $100 \%$ & 188 & $100 \%$ & 12 \\
\hline
\end{tabular}

Fuente: Elaboración propia

Tabla 11. Descripción porcentual de los resultados obtenidos a la pregunta 8 .

\begin{tabular}{|c|c|c|c|c|c|c|c|c|}
\hline \multirow{2}{*}{$\begin{array}{l}\text { P8: Relacione el ítem que } \\
\text { considere con máxima afinidad } \\
\text { entre turismo, paz y } \\
\text { convivencia en Ibagué. }\end{array}$} & \multicolumn{8}{|c|}{ Estratos } \\
\hline & Bajo & $\mathbf{N}$ & $\begin{array}{c}\text { Medio } \\
\text { bajo }\end{array}$ & $\mathbf{N}$ & $\begin{array}{c}\text { Medio } \\
\text { med. }\end{array}$ & $\mathbf{N}$ & Alto & $\mathbf{N}$ \\
\hline 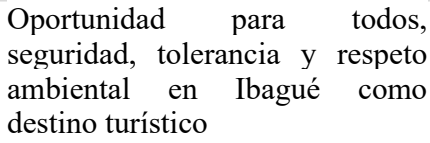 & $54 \%$ & 25 & $40 \%$ & 55 & $39 \%$ & 74 & $67 \%$ & 8 \\
\hline $\begin{array}{l}\text { Emprendimientos, empresas } \\
\text { comunitarias y participación } \\
\text { ciudadana en la administración } \\
\text { del patrimonio cultural y natural }\end{array}$ & $14 \%$ & 6 & $24 \%$ & 33 & $32 \%$ & 60 & $25 \%$ & 3 \\
\hline $\begin{array}{l}\text { Educación, campañas } \\
\text { preventivas de enfermedades, } \\
\text { cuidado de jardines comunitarios } \\
\text { y patrimonio natural }\end{array}$ & $6 \%$ & 3 & $12 \%$ & 16 & $6 \%$ & 12 & $8 \%$ & 1 \\
\hline $\begin{array}{l}\text { Finalización del conflicto } \\
\text { armado, oportunidad para todos, } \\
\text { desarrollo sostenible }\end{array}$ & $9 \%$ & 4 & $14 \%$ & 20 & $17 \%$ & 30 & & \\
\hline Otra & $17 \%$ & 8 & $10 \%$ & 14 & $6 \%$ & 12 & & \\
\hline Total & $100 \%$ & 46 & $100 \%$ & 138 & $100 \%$ & 188 & $100 \%$ & 12 \\
\hline
\end{tabular}

Fuente: Elaboración propia

La encuesta presenta una clara prueba del papel poco representativo que desempeñan los políticos en la ciudad, el porcentaje en todos los estratos supera el $40 \%$. Resaltan la falta de interés para apoyar la participación ciudadana y el desconocimiento de la participación ciudadana, "Según la encuesta del Latinobarómetro (1996-2011), los partidos políticos son sistemáticamente las instituciones en las que menos confían los latinoamericanos" (Welp y Mazurca, 2016:201). Las respuestas pueden obedecer a un claro reflejo del descontento por sus comportamientos, que han dado lugar a ser tildados de organizaciones democráticas oportunistas y de ahí, la desconfianza y el descontento. Sin embargo, relacionando estas respuestas con la pregunta 1 y 2 del cuestionario, donde reflejan un importante 
interés de trabajar para la comunidad y con los vecinos, lo que indica el interés para participar en la resolución de problemas locales, mas no saben cómo hacerlo porque siempre debe tener el aval del dirigente político y de las demás instancias que permanentemente están presentando obstáculos y no soluciones, argumentando la falta de capacidades de la comunidad cuando se trata de presentar proyectos. Así,

“(...) en los últimos años el sistema político ha visto cómo la lógica electoral ha desplazado a la lógica de la representación, cómo los partidos han ido dejando de cumplir eficazmente sus funciones y cómo, de forma paralela a la creciente desconfianza ciudadana sobre las organizaciones partidistas, la sociedad ha ido movilizándose hacia un creciente interés y deseo de participación política" (Flórez Giménez, 2015:374-375).

La muestra relaciona el turismo la paz y la convivencia en un espacio en donde se gesten oportunidades para todos, seguridad, tolerancia y respeto ambiental en Ibagué como destino turístico, los porcentajes más altos los presenta el estrato alto en un $67 \%$, seguido del bajo en un $54 \%$. Se toma esta respuesta para estudiar iniciativas que reorienten el desarrollo del turismo en la ciudad de Ibagué en un marco de sostenibilidad, en donde cada dimensión refleje su dinámica: Económica permitiendo la oportunidad para todos en el impulso, gestión y disfrute del turismo; Social: permitiendo la seguridad ciudadana en todas sus manifestaciones; cultural: impulsando los valores ciudadanos que nos lleven a la tolerancia, el respeto para fomentar desarrollo y la protección ambiental: reduciendo los impactos tanto del sector productivo como de la comunidad e impulsar la consciencia ambiental en Ibagué como destino turístico.

\subsection{Representación de los datos según modelo iceberg (enfoque sistémico)}

Es necesario precisar que, al referirnos a la idea de la participación ciudadana como factor, el significado de este concepto se asume ya no desde una posición estadística tradicional, sino que se le concibe desde el papel que juega la participación ciudadana en lo local. Siguiendo a Carpio (2013), se trata de concebir lo local como frontera que sirve de marco para aportar lo singular, lo propio que tiene una colectividad humana particular, que habita un lugar y transforma su territorio de acuerdo con las creencias que desarrolla e institucionaliza sobre los mismos. Dichas creencias son el producto de modelos mentales estabilizados, institucionalizados (Caballero-Miguez, 2009), de los que aquí se puede tener una primera versión sistémica que se traduce en la identificación de patrones, regularidades que explican la forma en que se sitúa la participación ciudadana, según los actores territoriales.

En esta línea sobresale del proceso de síntesis, que, sin importar el estrato socioeconómico, las proposiciones que reciben el mayor porcentaje son las mismas en cada estrato (figura 3). En otras palabras, es posible que estos modelos mentales se hayan estabilizado hasta el punto mismo que ciertas situaciones terminan viéndose como naturales, constituidas como instituciones particulares. 
Figura 3. Niveles de la realidad sobre el desarrollo del turismo en Ibagué y la participación ciudadana como factor asociado.

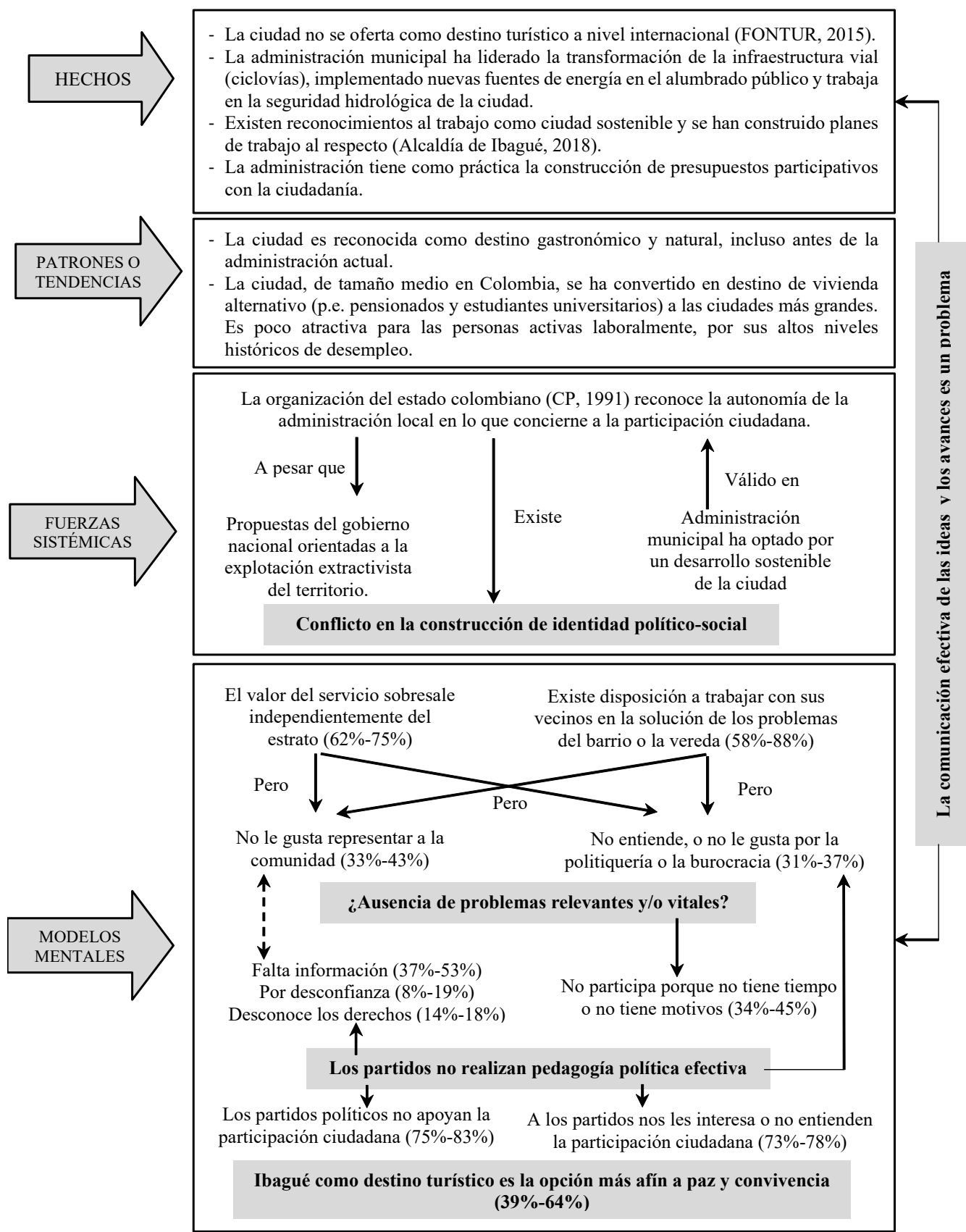

Fuente: Elaboración propia 
En el nivel modelos mentales (figura 3) se identifica claramente que a pesar de existir la vocación del servicio (con una mínima de $62 \%$ en un estrato y una máxima de $75 \%$ en otro), esta no es suficiente para participar activamente en la solución de los problemas de la ciudadanía. Si se sabe que la sociedad colombiana posee problemas vitales insatisfechos, lo que no es un secreto, ¿por qué existen ciudadanos que se excusan en la falta de tiempo o simplemente no tienen motivos para participar? Si se acepta que todos los ciudadanos poseemos necesidades vitales, especialmente en nuestro país, posiblemente estos ciudadanos "no ven" dichos problemas, y se concentran en el desarrollo de sus propias vidas individuales. De manera complementaria, la falta de información, por desconfianza o porque no desconocen los derechos, revelan que dicha hipótesis es razonable.

Si se sintetizan los dos resultados anteriores, es posible inferir aquí condiciones que llevan a plantear que la formación política de los ciudadanos de la muestra no incorpora de forma clara los problemas locales; es como un estar sin conocer el lugar. En este punto se hace evidente la falta de protagonismo de los partidos políticos (Welp y Mazurca, 2016:201), especialmente cuando de formar a los ciudadanos sobre los problemas locales se trata. Ahora es fácil reconocer, como se ha planteado en el nivel fuerzas sistémicas, que existe un conflicto en la construcción de la identidad socio-política que opera en el plano de lo nacional, fuera de lo local. Aunque es viable pensar que existe un problema de comunicación de parte de los partidos, también es posible plantear como explicación razonable que la comunicación puede ser efectiva, pero se hace despreocupándose de lo que sucede localmente, ya sea como consecuencia de nuestros propios modelos mentales o porque intencionalmente se deslocaliza a los ciudadanos como una forma de mantener el poder sobre ellos. En este escenario explicativo encaja consistentemente el tipo de ideas que amplificaron los diferentes partidos en relación con los procesos de paz con las Farc. Mientras los partidos de derecha usaron con frecuencia referencias a los ideales de nación ${ }^{9}$ y a las faltas cometidas por los integrantes de las guerrillas, como soporte para invitar a los ciudadanos a votar en contra de los acuerdos de paz; los partidos de izquierda y algunos de centro apelaron a las problemáticas locales, pero con la dificultad de que en los discursos nacionales no necesariamente son compartidas por todos.

En el marco del conflicto en la construcción de identidad socio-política, la administración local está en manos de un partido de mayor afinidad con la izquierda política, consecuencia de una decisión popular que le ha entregado el mandato de la ciudad para el periodo 2016-2019. En todo este periodo, aunque mayoritariamente los resultados indican que los ciudadanos asocian turismo con paz y convivencia, no necesariamente las actuaciones significativas de la administración municipal por conocer y solucionar los problemas locales tienen un futuro garantizado. De hecho, podría decirse que de alguna manera la frontera de lo local (Carpio, 2013) se expresa

${ }^{9}$ Con un conflicto previo entre los valores de corte feudalista y los emergentes valores liberales, vigente desde los años cincuenta en el país. 
como una guerra intestina por dos posiciones generales que se quieren quedar con las administraciones locales, departamentales, nacionales en las ramas judicial, ejecutiva y legislativa: una posición emergente que rescata lo local como fundamento de las propuestas políticas, entendiendo que los ciudadanos deben estar allí incluidos; $\mathrm{y}$ otra, una posición que banaliza lo local, y termina por imponer modelos utilitaristas en el uso del territorio.

En relación con la institucionalización de los partidos y frente a estas posiciones, en los modelos mentales es posible apreciar la forma en que los ciudadanos se sustraen de la organización política. De esta manera, la falta de comunicación y pedagogía forma un bucle retroalimentador con la ausencia intencional que los ciudadanos tienen del proceso de participación en la solución de sus problemas. En esta configuración de la participación, la disputa por el conocimiento de lo local parece protagónico (figura 4).

Figura 4. Bucle retroalimentador entre partidos políticos y ciudadanos en la construcción de participación ciudadana.

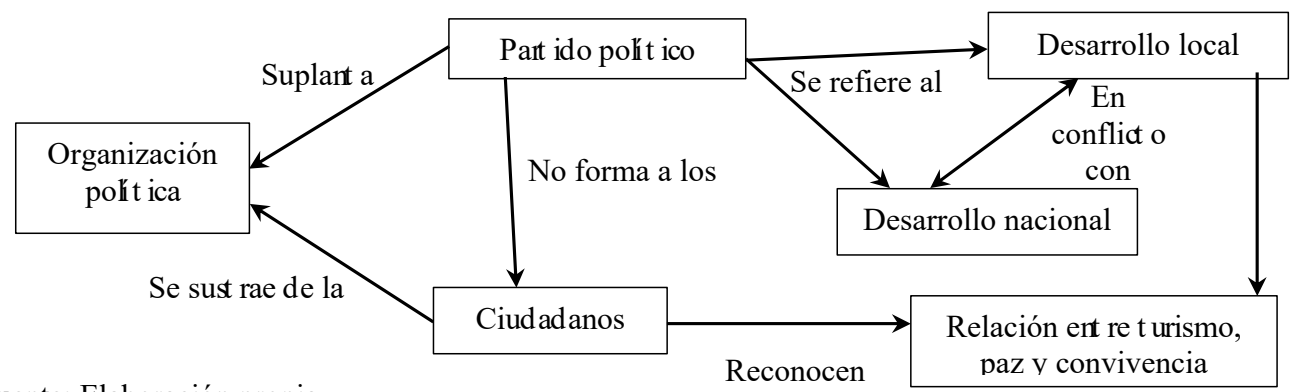

Fuente: Elaboración propia

De esta manera, en la práctica el ser político se ha convertido en una profesión. No todas las personas pueden ejercerlo, por lo que, al aislarse los ciudadanos de la organización política del estado, se presenta institucionalmente un proceso de suplantación de las organizaciones por parte de los partidos políticos. Así, los políticos y los partidos se ocupan de sus propias cosas, haciendo factible -y explicable desde los modelos mentales identificados- que institucionalmente se actúe de dicha manera, sin que apenas se profieran mayores reclamos, pero sí críticas, al respecto. Así, en esta muestra de ciudadanos, aunque es posible mencionar que se crítica la lógica representacionalista en política, no necesariamente los lleva a ser más activos en la vida política de la ciudad, en contra de lo que afirma Flórez Giménez (2015:374-375) en un contexto más general.

En este punto, también se hace necesario manifestar que la administración municipal ha focalizado los modelos de participación en comunidades desfavorecidas, coherente con sus raíces políticas. Los resultados aquí obtenidos son limitados en relación con este tipo de participación, pero sí es preocupante que aquellos ciudadanos sobre los que no se focaliza dicha participación, se sientan ahora excluidos y terminen por calificar este tipo de propuestas como "populistas"; lo que 
quitaría respaldo ciudadano a iniciativas de desarrollo sostenible que, desde nuestra perspectiva, son pertinentes.

\section{Conclusiones y reflexiones finales}

Sorprende identificar que los resultados que mayor porcentaje obtienen son iguales en cualquiera de los estratos. Desde la perspectiva de los modelos mentales, los datos aparecen consistentes con la tesis de Caballero-Miguez (2009:18): se institucionalizan los modelos mentales que se consideran solución a problemas recurrentes de interacción social.

En el enfoque analítico de los resultados es posible establecer algunos problemas puntuales, pero un enfoque sistémico de los mismo ha provocado una configuración rica y consistente sobre la forma que dichos niveles de explicación de la realidad se relacionan. Se destaca la identificación de un bucle retroalimentador (figura 4) en el que los partidos políticos no forman a los ciudadanos, que expresan su deseo de participar; y viceversa, los ciudadanos se sustraen de los partidos políticos de manera intencional. De esta manera, la participación ciudadana en la construcción de un turismo sostenible se ve limitada a la relación entre turismo, paz y convivencia, pero no necesariamente porque los ciudadanos estén informados profundamente de dichas problemáticas a nivel local.

En este bucle, la preocupación por lo local como frontera de trabajo desde la geografía humana (Carpio, 2013), se expresa en todo su esplendor. El conflicto en la construcción de identidad político-social, que hunde sus bases en el conflicto entre el desarrollo local frente al desarrollo nacional, como discurso pedagógico, parece uno de los elementos claves para la intención de mejorar los niveles de participación ciudadana en el desarrollo local en una concepción sostenible.

Finalmente, y bajo el entendido que se defiende aquí la institucionalización de modelos mentales en un bucle retroalimentador que explica los bajos niveles de participación ciudadana -en este caso de una muestra con aproximadamente $81 \%$ de estudiantes universitarios-, es motivo suficiente para cuestionarnos desde las instituciones educativas sobre las maneras en que formamos a nuestros ciudadanos para que conozcan el territorio y los lugares que habitan desde una perspectiva de desarrollo local. Este grupo de la población será fundamental en el desarrollo futuro del territorio y, en consecuencia, la transformación de sus modelos mentales es relevante en la institucionalización de nuevas formas de apreciar el desarrollo local, en este caso del turismo sostenible.

\section{Referencias bibliográficas}

Aguilar Idáñez, M. J. (2000). La participación comunitaria en salud: ¿mito o realidad?: evaluación de experiencias en atención primaria. Madrid, Ediciones Díaz de Santos. 
Aguirre Sala, J. F. (2014). El potencial de los medios digitales ante la participación ciudadana tradicional y en el presu-puesto participativo. Comunicación y Sociedad, 22, 211-229.

Alcaldía de Ibagué (2016). Plan de desarrollo 2016-2019. Disponible en http://www.alcaldiadeibague.gov.co/portal/admin/archivos/publicaciones/2016/14024PLA-20160502.pdf

Alcaldía Municipal de Ibagué (2014). Plan de Ordenamiento Territorial del Municipio de Ibagué, Departamento del Tolima”. Disponible en http://www.alcaldiadeibague.gov.co/portal/admin/archivos/normatividad/2015/11943-

DEC-20151002.pdf

Alcaldía Municipal de Ibagué (2018). Ibagué sostenible 2037. Territorio conector, colectivo y competitivo.

Disponible

en: https://www.ibague.gov.co/portal/admin/archivos/publicaciones/2018/21195-DOC20180814.pdf

Álvarez Álvarez, L.; Marrugo Padilla, A.; Barrera, E.A.; Serrato Arengas, K.; Rodríguez Giraldo, M.; Jiménez Cantillo, A. (2014). La participación ciudadana como ejercicio de aproximación a la construcción de cultura ciudadana en el marco del derecho y el deber. Análisis político, 81, 64-79. Disponible http://www.scielo.org.co/pdf/anpol/v27n81/v27n81a05.pdf

Araujo, K.; Martuccelli, D. (2015). Las individualidades populares Análisis de sectores urbanos en Chile. Latin Ameri-can Research Review, 50(2), 86-106. Disponible en https://lasa.international.pitt.edu/LARR/prot/fulltext/vol50no2/50-2_86-106_AraujoMartuccelli.pdf

Caballero Miguez, G. (2009). El papel de las instituciones en la geografía humana. Economía, Sociedad y Territorio, IX(29),1-31.

Caracol Radio Ibagué (2018). Ibagué es reconocida mundialmente en materia de sostenibilidad. Consultado el día 30 de marzo de 2019. Disponible en https://caracol.com.co/emisora/2018/06/29/ibague/1530297563 677157.html

Carpio Martín, J. (2013). Fronteras de la Geografía Humana en América Latina. En Jiménez Blasco, B. et al. (Coord.): Fronteras de $\mathrm{I}+\mathrm{D}+\mathrm{i}$ en Geografía Humana. Madrid, Departamento de Geografía Humana, Universidad Complutense de Madrid.

Chica Gómez, S-M.; Galvis Gutierrez, D.M; Ramírez Hassan, A. (2010). Determinantes del rendimiento académico en Colombia. Pruebas ICFES - Saber 11o, 2009. Revista Universidad EAFIT. http://publicaciones.eafit.edu.co/index.php/revista-universidadeafit/article/view/754

CIMPP de Ibagué (2019). Consulta sobre superficie de Ibagué. Consulta hecha el 20 de marzo de 2019. Disponible en https:/cimpp.ibague.gov.co/aspectos-generales/

CODESPA (2013) Programa Rutas: La apuesta por un turismo inclusivo en Latinoamérica. Disponible en http://www.codespa.org/blog/publicaciones-notas-tecnicas/programa-rutasla-apuesta-por-un-turismo-inclusivo-en-

latinoamerica/?gclid $=$ CJbYov_TodMCFUdkhgodw9sBRQ

Concejo Municipal de Ibagué (2014). Acuerdo 020. Disponible en http://www.alcaldiadeibague.gov.co/portal/admin/archivos/normatividad/2014/11786ACU-20150928.pdf

Congreso de Colombia (1994). Ley 142 de 1994. 
https://www.dane.gov.co/files/dig/ley142_1994.pdf

Congreso de la República de Colombia (1991). Constitución Política de Colombia. Gaceta Constitucional No. 116 de 20 de julio de 1991.

Cortolima (2010) Agenda Ambiental del Municipio de Ibagué, Disponible en http://www.cortolima.gov.co/sites/default/files/images/stories/centro_documentos/estudios /agendas/2010_Agenda_Ambiental_del_Municipio_de_Ibague_2010_Completa.pdf

Cortolima (2012). Plan de Gestión Regional del Tolima 2013-2023. Cortolima. Disponible en https://www.cortolima.gov.co/sites/default/files/images/stories/boletines/nov2012/PGAR_ 2013_2023_TOLIMA_01_12_12.pdf

Del Tronco, J. (2013). Desconfianza y Accountability: ¿las causas del populismo en América Latina?. Latin American Research Review, 48(2), 55-78. Disponible en http://lasa4.univ.pitt.edu/LARR/prot/fulltext/Vol48no2/48-2_55-78_tronco.pdf

Flórez Giménez, F (2015). Los partidos políticos: intervención legal y espacio político, a la búsqueda del equilibrio. Teo-ría y Realidad Constitucional, 35, 355-381.

Fondo de Promoción Turística del Tolima (2012). Plan de Desarrollo Turístico del Tolima. Colombia, Ministerio de Comercio, Industria y Turismo. Disponible en http://www.citur.gov.co/upload/publications/documentos/185.Plan_de_desarrollo_turistico del_Tolima.pdf

FONTUR (2015). Diseño del producto turístico Ibagué "Capital musical de Colombia". Disponible en https://www.fontur.com.co/aym_document/aym_estudios_fontur/PRODUCTO_TURISTI CO_DE_IBAGUE.PDF

Gan, F. y Triginé, J. (2012). Motivación. Madrid, Ediciones Díaz de Santos.

Liévano Martínez y Londoño (2012) El pensamiento sistémico como herramienta metodológica para la resolución de problemas. Escuela de Ingeniería de Antioquia. Disponible en https://repository.eia.edu.co/bitstream/11190/689/1/RSO00081.pdf

Murcia, C.; Morales Valderrama, A.; Ramírez-Casallas, J.F. (2015). Formación para el emprendimiento en estudiantes de Administración de Empresas. Revista Educación y Humanismo, 17(28),47-63. DOI: http://dx.doi.org/10.17081/eduhum.17.28.1166

Murcia, C.; Ramírez-Casallas, J.F.; Valderrama, O.C. y Morales Valderrama, A.A.; (2017). Tursimo sostenible: una conceptualización de su viabilidad para el municipio de Ibagué, desde un estado del arte pertinente. PASOS-Revista de Turismo y Patrimonio cultural, 15(1),21-34. DOI: https://doi.org/10.25145/j.pasos.2017.15.002

Ortega-Montes, J.E.; Valencia-Jiménez, N.N.; Restrepo-Valencia, M. (2008). La economía política de la pobreza y la desigualdad social: el caso de Montería. Cuadernos de Vivienda y Urbanismo, 1(1), 96-123.

Piñuel Raigada, J.L. (2002). Epistemología, metodología y técnicas de análisis de contenido. Estudios de Sociolingüística, 3(1), 1-42. Disponible en https://www.ucm.es/data/cont/docs/268-2013-07-29-

Pinuel_Raigada_AnalisisContenido_2002_EstudiosSociolinguisticaUVigo.pdf

Prieto-Martín, P y Ramírez-Aluja, A. (2014). Caracterizando la participación ciudadana en el marco del Gobierno Abierto. Revista del CLAD Reforma y Democracia, 58,61-100.

Ramírez Casallas, J.F. (2010). La Investigación Formativa en la Universidad Cooperativa de Colombia de Ibagué: identificación de problemas institucionales asociados. Revista 
Nacional de Investigación-Memorias, 8(13), 201-215. Disponible en: https://www.researchgate.net/publication/322397100_La_Investigacion_Formativa_en_la_ Universidad_Cooperativa_de_Colombia_de_Ibague_identificacion_de_problemas_instituc ionales asociados

Ramírez Casallas, J.F.; Ramírez Arcila, H. (2018). Aportes en la construcción de competencias de la práctica profesional de ingenieros civiles en formación, desde el enfoque del Profesional Reflexivo. Estudio de caso. Revista Prácticum, 3(2),1-21. Disponible en https://revistapracticum.com/index.php/iop/article/view/52/91

Segrelles Serrano, J.A. (2018). La desigualdad en el reparto de la tierra en Colombia: Obstáculo principal para una paz duradera y democrática. Anales de Geografía, 38(2), 409433.

Senge, P; Laur, J.; Schley, S.; Smith, B. y Kruschwitz, N. (2009). La Revolución Necesaria: Cómo individuos y organiza-ciones trabajan por un mundo sostenible. Bogotá, Editorial Norma.

Soares, J. C., Gandara, J. M. e Ivars, J. A (2015). La evolución de destinos turísticos litorales consolidados. Análisis comparado de Balneario Camboriú (Brasil) y Benidorm (España). Anales de Geografía, 35(2 ),143-166.

Stake, R.E. (1999). Investigación con estudio de casos. Madrid. Morata.

Velásquez C.F y González R. E. (2003). ¿Qué ha pasado con la participación ciudadana en Colombia? Disponible en

http://www.dhl.hegoa.ehu.es/ficheros/0000/0120/participacion_ciudadana_en_colombia.pdf

Welp, Y; Mazurca, A. (2016). Presencia de partidos políticos y diputados en Internet en Argentina, Paraguay y Uru-guay. Perfiles Latinoamericanos, 24(47), 199-224 DOI: 10.18504/p12447-011-2016

Yubero Bernabé, C y García Hernández, M. (2016) Turismo en Albarracín y Comarca. Acción pública local y dinámica reciente en clave de desarrollo turístico sostenible. Anales de Geografía, 36(1), 173 - 194.

Zulaica, L.; Tomadoni, M. (2015). Indicadores de sostenibilidad ambiental en el periurbano de Mar del Plata, Argentina. Anales de Geografía, 35(2), 195-216. http://dx.doi.org/10.5209/rev_AGUC.2015.v35.n2.50120. 